\title{
A UTILIZAÇÃO DA CONTABILIDADE COMO FERRAMENTA NA GESTÃO DAS FINANÇAS PESSOAIS: ESTUDO COM OS DISCENTES DE FACULDADE PARTICULAR DO OESTE DO PARANÁ
}

\author{
Vitor Rafael Goetz ${ }^{1}$ \\ Lucas Gabriel de Almeida ${ }^{2}$ \\ Elisiane Salzer ${ }^{3}$ \\ Alexandre Feiden ${ }^{4}$ \\ Jessica Karine de Oliveira Gomes ${ }^{5}$
}

GOETZ, V. R.; ALMEIDA, L. G. de; SALZER, E.; FEIDEN, A.; GOMES, J. K. de O. A utilização da contabilidade como ferramenta na gestão das finanças pessoais: estudo com os discentes de faculdade particular do oeste do Paraná. Revista de Ciências Empresariais da UNIPAR, Umuarama, v. 22, n. 1, p. 6589, jan./jun. 2021.

RESUMO: As consequências advindas com a pandemia da COVID-19 desaceleraram a economia mundial, devido a uma brusca queda das atividades industriais, comerciais e de serviços. A educação financeira pode auxiliar os indivíduos e famílias na administração das suas finanças pessoais, especialmente em momentos de crise. Assim, o objetivo deste estudo é analisar se os discentes da Faculdade de Ensino Superior - Isepe Rondon, utilizam a contabilidade como ferramenta na gestão das finanças pessoais e qual a percepção desses frente à relevância da educação financeira nos cursos superiores. Para atingir o objetivo proposto, a metodologia utilizada tem caráter descritiva baseada em um estudo de caso qualitativo e quantitativo, com aplicação de questionário aos discentes da instituição. Após análise dos dados, constatou-se que 54,7\% dos acadêmicos fazem utilização de ferramentas, como planilhas ou aplicativos, para controle das finanças pessoais e $87,1 \%$ acreditam que o tema deve ser trabalhado durante a graduação. Conclui-se que os acadêmicos da instituição possuem um bom conhecimento frente ao tema, utilizam as ferramentas contábeis para os controles financeiros, possuem um baixo nível de endividamento e consideram importante o ensino de finanças pessoais durante o curso superior.

PALAVRAS-CHAVE: Gestão Financeira; Finanças Pessoais; Contabilidade.

DOI: https://doi.org/10.25110/receu.v22i1.8416

${ }^{1}$ ISEPE. Rondon/Graduado. E-mail: vitorgoetz@hotmail.com

${ }^{2}$ ISEPE. Rondon/Graduado. E-mail: lucasgabrieldealmeida@outlook.com

${ }_{3}^{3}$ ISEPE. Rondon/Graduado. E-mail: s_elisiane@yahoo.com.br; https://orcid.org/0000-0002-88988097

${ }_{4}^{4}$ ISEPE. Rondon/Docente. E-mail: alexfeiden@hotmail.com

${ }^{5}$ ISEPE. Rondon/Docente. E-mail: jekarine@outlook.com 


\title{
ACCOUNTING AS A MANAGEMENT TOOL IN PERSONAL FINANCES: STUDY WITH STUDENTS FROM A PRIVATE COLLEGE IN WESTERN PARANÁ
}

\begin{abstract}
The uncertain consequences arising from the COVID-19 pandemic slowed the world's economy due to a sharp drop in industrial, commercial, and service provision activities. Financial education can assist individuals and families in managing their personal finances. Thus, the objective of this study is to analyze whether students from the Faculty of Higher Education - Isepe Rondon, use accounting as a tool in the management of personal finances and what their perception is regarding the relevance of financial education in higher education courses. It uses a descriptive methodology based on a qualitative and quantitative case study, with the application of a questionnaire to the students of the institution. After the data was analyzed, it was found that $54.7 \%$ of the students use tools such as spreadsheets or applications to control personal finances, and $87.1 \%$ believe the topic should be presented as a discipline during undergraduate courses. It can be concluded that the students in that institution have a good knowledge on the subject, use the accounting tools for financial controls, have a low level of indebtedness, and consider the teaching of personal finances important during higher education.

KEYWORDS: Financial Management; Personal finances; Accounting.

\section{EL USO DE LA CONTABILIDAD COMO HERRAMIENTA EN LA GESTIÓN DE FINANZAS PERSONALES: ESTUDIO CON ESTUDIANTES DE UNA FACULTAD PRIVADA EN EL OESTE DE PARANÁ}

RESUMEN: Las incertidumbres derivadas con la pandemia de COVID-19 desaceleraron la economía mundial, debido a una fuerte caída de las actividades industriales, comerciales y de servicios. La educación financiera puede ayudar a las personas y familias a administrar sus finanzas personales en momentos de crisis. Así, el objetivo de este estudio es analizar si los estudiantes de la Facultad de Educación Superior - Isepe Rondon, utilizan la contabilidad como herramienta en el manejo de finanzas personales y cuál la percepción de ellos sobre la relevancia de la educación financiera en los cursos de educación superior. Para lograr el objetivo propuesto, la metodología utilizada tiene un carácter descriptivo de investigación a partir de un estudio de caso cualitativo y cuantitativo, con la aplicación de un cuestionario a los estudiantes de la institución. Luego de analizar los datos, se encontró que el 54,7\% de los académicos utilizan herramientas, como hojas de cálculo o aplicaciones, para controlar las finanzas 
personales y el $87,1 \%$ creen que se debe trabajar el tema durante la graduación. Se concluye que los académicos de la institución tienen un buen conocimiento sobre el tema, utilizan las herramientas contables para los controles financieros, tienen un bajo nivel de endeudamiento y consideran importante la enseñanza de finanzas personales durante la educación superior.

PALABRAS CLAVE: Gestión financiera; Finanzas personales; Contabilidad.

\section{INTRODUÇÃO}

Considerando a situação econômica e financeira do país, e o impacto da pandemia do coronavírus, fica visível a importância e a necessidade das pessoas administrarem seus rendimentos de forma produtiva e enriquecedora. A administração das finanças pessoais ajuda na adequação do padrão de vida, gastando somente o que cabe no seu orçamento evitando exageros. A contabilidade é uma ferramenta importante nesse contexto, pois através de seus demonstrativos e técnicas pode-se visualizar as rendas, despesas e o resultado final. Com uma boa gestão das finanças pessoais é possível ter uma vida financeira mais equilibrada e planejada.

Gestão das finanças pessoais, por meio da contabilidade, é de suma importância, pois através dela pode-se ter um controle assertivo das finanças que envolvem as pessoas de determinada sociedade. Esses controles podem ser feitos de diversas formas como, por exemplo, desde uma simples planilha de controle de custos e despesas, até um demonstrativo contábil.

A contabilidade é como um mecanismo de gestão para diversas atividades, pois ela tem como função controlar o patrimônio das pessoas físicas e jurídicas por meio de técnicas, como por exemplo, a elaboração de demonstrações contábeis, que auxilia na gestão das finanças pessoais. A contabilidade pessoal permite que a pessoa tenha uma visão ampliada de todas suas receitas e despesas em um aspecto familiar, facilitando a administração dos ganhos e também na tomada de decisões relacionadas às finanças (MARION, 2004).

Porém, a contabilidade pessoal não é muito utilizada pela sociedade, pois muitas pessoas não fazem o controle de seus gastos semanais, mensais e anuais. Dessa maneira, perde-se o equilíbrio econômico e financeiro pessoal, causando endividamentos desnecessários.

O ensino da educação financeira nas escolas é de suma importância, o que possibilita o maior contato de pessoas com finanças e, assim, ajuda na formação de jovens conscientes em relação ao dinheiro e capazes de tomarem melhores decisões relacionadas a investimentos e financiamentos, o que contribui para a melhoria da qualidade de vida (STEIGER; BRAIDO, 2016).

Lopes et al. (2014) buscaram mensurar o grau de alfabetização financeira 
dos universitários de administração, ciências contábeis e ciências econômicas da Fecap, almejando determinar se os alunos colocam em prática o que aprendem na teoria.

De Queiroz, Valdevino e Oliveira (2015), em pesquisa desenvolvida, buscaram analisar o uso da contabilidade na gestão das finanças pessoais, de forma comparativa entre duas instituições de ensino com alunos do curso de ciências contábeis, e sugeriram realizar novas pesquisas com um número maior de discentes e de instituições de ensino diferentes.

Diante do exposto, surge o seguinte questionamento: Os discentes da Faculdade de Ensino Superior - Isepe Rondon, utilizam a contabilidade como ferramenta na gestão das finanças pessoais e qual a percepção desses frente à relevância da educação financeira nos cursos superiores?

O objetivo do presente estudo é analisar se os discentes da Faculdade de Ensino Superior - Isepe Rondon, utilizam a contabilidade como ferramenta na gestão das finanças pessoais e qual a percepção destes frente à relevância da educação financeira nos cursos superiores. Para atingir o objetivo geral, determinaram-se os seguintes objetivos específicos: identificar o perfil dos acadêmicos; averiguar de qual maneira os acadêmicos aprenderam sobre a educação financeira; identificar a visão dos acadêmicos da instituição referente à educação financeira; verificar se os discentes guardam parte de sua renda para investimentos; examinar o nível de conhecimento dos acadêmicos em relação às finanças pessoais.

O estudo se torna relevante, pois as ferramentas contábeis são de suma importância para a gestão das finanças pessoais, como intuito de auxiliar na tomada de decisão e, principalmente, no controle das receitas e gastos. $\mathrm{O}$ estudo deste tema auxilia para que mais pessoas tenham consciência deu seu futuro financeiro por meio de um bom planejamento, mantendo estabilidade na questão econômico-financeira.

\section{REFERENCIAL TEÓRICO}

Esta seção trata dos fundamentos teóricos em que se embasa a pesquisa. Para tanto, abordam-se os seguintes temas: contabilidade; contabilidade pessoal; educação financeira e estudos anteriores desenvolvidos sobre a temática.

\subsection{Contabilidade}

A contabilidade é o instrumento que fornece informações úteis para a tomada de decisões dentro e fora da empresa. Ela é muito antiga e sempre existiu para auxiliar as pessoas a tomarem as decisões. Com o passar do tempo o governo começou a utilizar-se dela para arrecadar impostos e a torna obrigatória para a 
maioria das empresas. A contabilidade foi criada com o objetivo de organizar economicamente uma empresa, e com o passar dos anos o governo tornou a contabilidade uma ferramenta de controle de impostos, para se ter o equilíbrio econômico do país (MARION, 1998).

Para Ferrari(2011), a contabilidade estuda e pratica funções de orientação, controle e registros com o objetivo de fornecer aos usuários demonstrações e análises econômico-financeiras. Já Marion (2004) afirma que a contabilidade pode ser feita para pessoa física ou pessoa jurídica, sendo que a pessoa física é a pessoa natural, o ser humano. Portanto, na prática, a contabilidade é mais utilizada por pessoas jurídicas, porém alguns conceitos básicos em determinadas situações são usados por pessoas físicas.

Segundo Oliveira (2009), a contabilidade desempenha um papel fundamental no âmbito econômico da organização, pois sem ela não seria capaz de se conhecer o passado e nem o futuro de uma determinada organização, minimizando os riscos e as incertezas, ou seja, sem a contabilidade não poderiam ser feitas previsões, e não se conseguiria elaborar planos para orientações administrativas.

Já, para o autor Franco (1997), a contabilidade tem por função registrar, classificar, demonstrar, auditar e analisar todos os fenômenos que ocorrem no patrimônio das entidades, objetivando fornecer informações, interpretações e orientação sobre a composição e as variações desse patrimônio. A contabilidade tem várias funções, porém entre as principais está também o planejamento e o controle.

Segundo Adriano (2012), a contabilidade é uma ciência enquadrada no ramo das ciências sociais e que tem por objeto o patrimônio das entidades, objetivando controlar esse patrimônio a fim de fornecer informações aos seus usuários. Ainda nesse sentido, Ferrari (2011, p. 2) afirma que "o campo de aplicação da contabilidade se estende a todas as entidades que possuam patrimônio, sejam físicas ou jurídicas, de fins lucrativos ou não".

Uma área de atuação da Contabilidade é a contabilidade tributária que está envolvida claramente ao estudo dos tributos e a legislação fiscal. De acordo com Fabretti (2009, p. 6), "é o ramo da contabilidade que tem por objetivo aplicar na prática os conceitos, princípios e normas básicas da contabilidade e da legislação tributária, de forma simultânea e adequada"

Para a empresa ou pessoa física ter um bom resultado é de fundamental que se faça o planejamento tributário anualmente. Conforme Pohlmann (2010) é considerado como planejamento tributário um conjunto composto por decisões e ações obtidas pelos contribuintes, tendo foco principal evitar a incidência de tributos, quando não conseguir evitar, tentar diminuir seu valor ou também conseguir prorrogar seu pagamento, com relação a específico ato, atividade 
ou negócio. Dessa forma se empresa ou pessoa tiver um bom planejamento tributário, consequentemente, irá ter mais economia em impostos e tributos, gerando, posteriormente, lucro para poder investir em que considerar melhor.

Conforme Andrade Filho (2015), apresenta-se a questão de a palavra planejamento tributário possuir dois sinônimos, um deles é a elisão fiscal ou elusão fiscal. Ou seja, é possível perceber que existe uma palavra contrária ao planejamento tributário que seria a evasão fiscal, ela está ligada à sonegação de impostos ou omissão, sendo assim, contra a lei.

Outra área da contabilidade é a financeira que, de acordo com Horngren (1985, p. 13), "[...] a contabilidade financeira enfatiza o preparo de relatórios de uma organização para usuários externos, como, por exemplo, bancos e o público investidor [...]".

Dessa forma, ela atua não só como uma ferramenta administrativa, mas também estratégica, pois ela nos fornece informações relevantes aos acionistas proprietários e possíveis parceiros, visto que monitora todas as alterações no patrimônio de uma empresa ou pessoa. Assegura-se que todas essas informações são coletadas de forma legal com os devidos requisitos fiscais.

Após essa análise é possível verificar a real rentabilidade que uma empresa tem e qual foi seu desempenho, de forma clara e objetiva. Relacionando com a Contabilidade Gerencial que segundo Pizzolato (2012, p. 195) "produz informação útil para a administração, a qual exige informações para vários propósitos tais como: auxílio no planejamento; na medição e avaliação de performance; na fixação de preços de venda e na análise de ações alternativas."

Conforme Sá (1971), a contabilidade gerencial, através de um sistema de informação, métodos e conhecimento da organização e da utilização do planejamento, fornece informações mais relevantes. Sem essas informações e orientações não seria possível a organização ter uma decisão concreta em determinado assunto empresarial, ou em âmbito pessoal, não seria capaz de ter um caminho a se tomar, diante de uma decisão ou escolha.

A contabilidade gerencial parte das informações existentes na contabilidade financeira e faz os complementos necessários para o uso dos gestores. As informações contábeis gerenciais devem ser apresentadas em relatórios desenvolvidos para cada tomada de decisão e adaptados para o perfil do usuário do relatório. Percebe-se que a contabilidade gerencial é bastante ligada à contabilidade financeira ela a utiliza e faz seus complementos (PADOVEZE, 2012).

A contabilidade de custos também é um ramo da contabilidade que, conforme Ribeiro (2013, p. 23), "O que torna a contabilidade de custos diferente dos demais ramos da contabilidade, são os procedimentos praticados na área de produção industrial, os quais exigem a aplicação de critérios específicos para se 
apurar o custo de fabricação". Ou seja, os custos são essenciais para poder gerar preços, avaliar estoque, alcançar competitividade, tomar decisões. Os custos de uma empresa nunca devem ser confundidos com custos pessoais, pois podem acarretar em uma mudança no quadro financeiro de uma empresa, acarretando custos desnecessários.

\subsection{Contabilidade pessoal}

A contabilidade pessoal demonstra-se relevante no próprio dia a dia dos cidadãos, pois todos os trabalhadores ou aposentados, ao efetuarem transações simples para saber quanto receberão ao final de um mês, estão fazendo Contabilidade pessoal (PARADA, 2011).

A contabilidade pessoal é o registro de todas as operações financeiras realizadas. Essas informações servem para que se tenha uma melhor gestão pessoal e financeira, o processo seria, em base, quase igual ao processo de uma empresa, coleta de dados, classificação, separação (organizar os dados em algum lugar de fácil entendimento), administrar a vida pessoal e financeira sobre os dados estudados e coletados pelo indivíduo. Para Macedo Junior (2007, p. 26), “o Planejamento Financeiro é o processo de gerenciar seu dinheiro com o objetivo de atingir a satisfação pessoal."

A contabilidade é um sistema de informação e avaliação que deseja demonstrar uma análise financeira, econômica, etc. Com isso, a tomada de decisão seria a parte em que a pessoa física analisa qual seria o melhor caminho a se tomar em determinada situação, com os dados coletados ela terá uma facilidade maior para ter uma assertividade em suas decisões financeiras (MARION, 1998).

Para Freitag et al. (2009), os alunos dos cursos superiores de ciências contábeis, acabam esquecendo de priorizar o motivo do surgimento da contabilidade que nada mais é que o controle de qualquer tipo de patrimônio e acabam por aplicar o conhecimento contábil apenas no âmbito empresarial. Isso demonstra que há realmente a necessidade de se usar os conceitos e técnicas contábeis aplicáveis às pessoas jurídicas, para as pessoas físicas.

Da Silva, Carraro e da Silva (2017) afirma que a contabilidade pessoal pode ser definida como a organização financeira do patrimônio de pessoas físicas. É o registro de todas as operações financeiras realizadas por uma pessoa. Essas informações são usadas para controlar e gerir as finanças pessoais. Essas operações envolvem os registros das aquisições de bens e direitos de uma pessoa. A necessidade da contabilidade para pessoas físicas se deve ao fato, de que ela visa fornecer informações sobre a situação financeira, com base nos fatos ocorridos no patrimônio, coletando dados e proporcionando a oportunidade da administração da sua própria vida financeira, observando possibilidade de economias extras de recursos, para futuros investimentos. 
Atualmente, a maioria das pessoas não costuma registrar suas despesas e receitas, como também não avalia a sua situação financeira antes de adquirir um bem, conforme constatou uma pesquisa nacional registrada no jornal Estado de São Paulo (2014). As consequências desses maus hábitos geram indivíduos os quais não conseguem pagar suas dívidas, além de não atingirem seus objetivos pessoais, tornando-se cada vez mais limitado sair dessa situação.

Segundo Macedo Junior (2007), os fatores históricos, como a falta de educação financeira no Brasil, anos de inflação, desinformação e erros cometidos por sucessivos governos do passado, resultaram em conceitos financeiros errôneos, absorvidos pela população. Ainda segundo o autor, sugere-se reformular os conceitos adquiridos, para se estar apto a enfrentar novos tempos, além de aumentar as chances de alcançar a independência financeira. Gallagher (2008, p. 4) afirma que "em nada adianta ter dinheiro se não sabemos desfrutá-lo".

Na visão de Sousa e Dana (2012), é necessário controlar os gastos, anotando-os na ocasião que ocorrerem, pois será mais fácil saber quanto se tem disponível de dinheiro em dado momento, reservando sempre o valor necessário para quitar as contas fixas, principalmente aquelas que possuem os juros mais altos, e adequar os demais gastos com a sua realidade financeira.

Dessa maneira, para alcançar os objetivos pessoais, faz-se necessário um controle das finanças, visto que por meio do planejamento é possível compreender os recursos adquiridos e utilizados, e também como esses serão investidos e gastos. Assim, um bom planejamento torna-se indispensável.

\subsection{Educação financeira}

A necessidade de educação financeira aumenta à medida que o setor financeiro se desenvolve, pois o aumento dos serviços e produtos financeiros e da tecnologia faz com que o mercado necessite de consumidores com mais conhecimentos a fim de tomarem decisões mais eficientes (MIRANDA, 2013). Ainda na opinião de Miranda (2013), a educação financeira pode ser vista como um investimento com ganhos tanto para o consumidor quanto para as entidades que oferecem esses serviços, pois quando o consumidor passa a conhecer bons métodos e práticas de gestão de finanças, ele passa a administrar melhor suas finanças e evolui, consideravelmente, em sua qualidade de vida e suas decisões financeiras.

Na visão de Negri (2010), a educação financeira pode ser definida como um processo educativo pelo qual são aplicados métodos próprios que desenvolvem atividades para auxiliar os consumidores a gerirem suas rendas, a pouparem e a investirem. Com isso, percebe-se que este tema é de suma importância para a sociedade, pois ele tem grande impacto nas finanças de cada família e também na economia nacional. 
Gilligan (2012) apresenta que a falta de educação financeira pode acarretar consequências no longo prazo para as pessoas, pois os indivíduos devem estar preparados para cuidar de suas finanças até mesmo antes de entrar para a faculdade, já que nessa fase é que eles entram para o mercado de trabalho e começam a planejar seu futuro.

Educação financeira pode qualificar os consumidores a serem melhores compradores, permitindo-os obter bens e serviços a custos menores. Esse processo, efetivamente, aumenta o poder de compra real do consumidor e provê maiores oportunidades para consumir mais, poupar ou investir. Além disso, a educação financeira pode auxiliar as pessoas a obterem ganhos de conhecimentos necessários para criar orçamentos familiares, iniciar planos de poupança, gerenciamento de débitos e formular decisões estratégicas de investimento para a sua aposentadoria ou para a educação de seus filhos (GREENSPAN, 2005).

Realizar um planejamento financeiro é adotar uma estratégia que tenha um foco. A estratégia tem como objetivo final acumulação de bens e valores, para que no futuro a pessoa consiga realizar metas estabelecidas, tanto financeiras quanto pessoal (MACEDO JUNIOR, 2007).

Para Gitman (2001), o planejamento financeiro é um aspecto importante das operações nas empresas e famílias, pois ele mapeia os caminhos para guiar, coordenar e controlar as ações das empresas e das famílias para atingir os objetivos. Dessa forma, quando a pessoa se assemelha a um planejamento financeiro, com determinação e consciência do que se está fazendo, o processo se torna mais fácil e concreto, sendo a própria pessoa o seu administrador.

São muitas as vantagens para aqueles que têm acesso à educação financeira, estes obtêm informações essenciais para o gerenciamento de suas finanças e podem realizar um planejamento financeiro adequado às suas necessidades e metas pessoais.

\subsection{Estudos anteriores}

Com o intuito de aprimorar e expandir o conhecimento sobre como as finanças pessoais e o uso da contabilidade que vem sendo abordado por estudantes, no Quadro 1 apresentam-se alguns dos estudos empíricos desenvolvidos anteriormente e relacionados com o tema deste artigo. 
Quadro 1: Estudos anteriores

\begin{tabular}{|c|c|c|}
\hline Autores & Objetivos & Principais Resultados \\
\hline $\begin{array}{l}\text { Alves, Silva e } \\
\text { Bressan (2011) }\end{array}$ & $\begin{array}{l}\text { Avaliar o nível de } \\
\text { educação financeira } \\
\text { de alunos do curso } \\
\text { de ciências contábeis } \\
\text { de uma instituição de } \\
\text { ensino superior privada } \\
\text { no Rio de Janeiro, em } \\
\text { conjunto com a oferta } \\
\text { de disciplinas visando } \\
\text { verificar a existência da } \\
\text { referida lacuna. }\end{array}$ & $\begin{array}{l}\text { Os resultados indicaram que a } \\
\text { maior parte dos alunos participantes } \\
\text { da pesquisa possui baixo nível de } \\
\text { conhecimento sobre o assunto e inferiu- } \\
\text { se que, além de não existir disciplinas } \\
\text { relacionadas à finanças corporativas } \\
\text { na grade curricular da instituição de } \\
\text { ensino pesquisada, o grau de educação } \\
\text { financeira dos participantes pode ser } \\
\text { considerado inadequado, facilitando a } \\
\text { formação de opiniões equivocadas que } \\
\text { prejudicam a decisão dos alunos em } \\
\text { relação à questões financeiras. }\end{array}$ \\
\hline $\begin{array}{l}\text { Vieira, Bataglia e } \\
\text { Sereia (2011) }\end{array}$ & $\begin{array}{l}\text { Analisar se a educação } \\
\text { financeira obtida junto } \\
\text { aos cursos de graduação } \\
\text { influencia na atitude } \\
\text { de consumo, poupança } \\
\text { e investimento dos } \\
\text { indivíduos. }\end{array}$ & $\begin{array}{l}\text { Verificou-se com a pesquisa que a } \\
\text { formação acadêmica contribui para } \\
\text { a melhor tomada de decisões de } \\
\text { consumo, investimento e poupança } \\
\text { dos indivíduos. Mas se constatou, } \\
\text { também, que existem outras fontes } \\
\text { de conhecimento que são igualmente } \\
\text { relevantes, como a experiência prática } \\
\text { e vivência da família. }\end{array}$ \\
\hline $\begin{array}{l}\text { Lopes et al. } \\
(2014)\end{array}$ & $\begin{array}{l}\text { Mensurar o grau de } \\
\text { alfabetização financeira } \\
\text { dos universitários de } \\
\text { administração, ciências } \\
\text { contábeis e ciências } \\
\text { econômicas da Fecap, } \\
\text { ou seja, determinar se } \\
\text { os alunos aplicam o que } \\
\text { aprendem na teoria. }\end{array}$ & $\begin{array}{l}\text { Os resultados demonstraram que } \\
\text { os estudantes são alfabetizados } \\
\text { financeiramente, com uma nota geral } \\
\text { de } 2,63 \text { tendo } 3 \text { como nota máxima. A } \\
\text { variável atitude financeira apresentou } \\
\text { um pior desempenho quando se trata } \\
\text { de investir para atingir metas de longo } \\
\text { prazo, concluindo que os alunos } \\
\text { visam o curto prazo. Na variável } \\
\text { comportamento financeiro o destaque } \\
\text { negativo foi que } 56 \% \text { dos alunos não } \\
\text { possuem uma reserva financeira maior } \\
\text { ou igual a três vezes a renda mensal } \\
\text { para ser usada em casos inesperados. }\end{array}$ \\
\hline
\end{tabular}




\begin{tabular}{|c|c|c|}
\hline $\begin{array}{l}\text { Medeiros } \\
\text { Lopes (2014) }\end{array}$ & 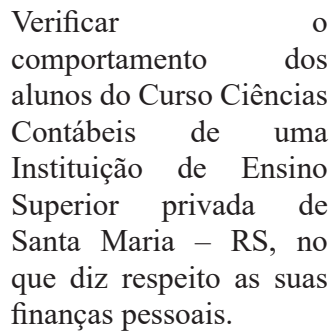 & $\begin{array}{l}\text { Os resultados apontaram que a maioria } \\
\text { dos alunos pesquisados demonstrou ter } \\
\text { consciência dos rendimentos ganhos, } \\
\text { bem como saber lidar com suas finanças } \\
\text { pessoais. Salienta-se ainda que, } \\
\text { geralmente, costumam pagar as suas } \\
\text { compras à vista, utilizando o dinheiro } \\
\text { como forma de pagamento. }\end{array}$ \\
\hline $\begin{array}{l}\text { Lizote e } \\
\text { Verdinelli (2014) }\end{array}$ & $\begin{array}{l}\text { Analisar as associações } \\
\text { entre o conhecimento } \\
\text { sobre finanças pessoais } \\
\text { e as características dos } \\
\text { estudantes do curso } \\
\text { de Ciências Contábeis } \\
\text { de uma universidade } \\
\text { comunitária do Estado } \\
\text { de Santa Catarina, cujo } \\
\text { perfil profissiográfico os } \\
\text { vincula ao uso adequado } \\
\text { dos recursos econômicos } \\
\text { e financeiros. }\end{array}$ & $\begin{array}{l}\text { Os resultados mostraram que os } \\
\text { maiores conhecimentos sobre educação } \\
\text { financeira são associados aos alunos } \\
\text { que trabalham quando comparados com } \\
\text { os que só estudam. A renda pessoal } \\
\text { é a característica que influencia mais } \\
\text { resultados. Os estudantes que possuem } \\
\text { maiores rendimentos gerenciam melhor } \\
\text { os empréstimos e financiamentos, } \\
\text { organizam de maneira mais adequada } \\
\text { suas dívidas e a gestão de ativos a } \\
\text { realizam mais apropriadamente. }\end{array}$ \\
\hline $\begin{array}{l}\text { Correia, Lucena } \\
\text { e Gadelha (2015) }\end{array}$ & $\begin{array}{l}\text { Identificar o nível de } \\
\text { Educação Financeira dos } \\
\text { estudantes de Ciências } \\
\text { Contábeis em cinco IES } \\
\text { de João Pessoa/PB, sendo } \\
\text { quatro privadas (A, B, C } \\
\text { e D) e uma pública (E) } \\
\text { no que diz respeito ao } \\
\text { comportamento quanto } \\
\text { às decisões de consumo e } \\
\text { investimento. }\end{array}$ & $\begin{array}{l}\text { Os respondentes em uma percentagem } \\
\text { considerável optaram pela estabilidade } \\
\text { nos retornos dos investimentos em } \\
\text { detrimento aos riscos. E dos que } \\
\text { afirmaram não possuir dívidas, muitos } \\
\text { alunos demonstram se preocupar com } \\
\text { a qualidade e preços dos produtos } \\
\text { que adquirem, bem como preferir a } \\
\text { estabilidade da poupança em detrimento } \\
\text { aos financiamentos. }\end{array}$ \\
\hline $\begin{array}{l}\text { De Queiroz, } \\
\text { Valdevino e de } \\
\text { Oliveira (2015) }\end{array}$ & $\begin{array}{l}\text { Analisar qual é a } \\
\text { percepção dos discentes } \\
\text { de Ciências Contábeis da } \\
\text { UERN e da UNP sobre } \\
\text { o uso da contabilidade } \\
\text { na gestão das finanças } \\
\text { pessoais. }\end{array}$ & $\begin{array}{l}\text { Os resultados mostraram que os } \\
\text { discentes da UERN consideram a } \\
\text { contabilidade mais relevante para } \\
\text { gestão das finanças pessoais do } \\
\text { que os discentes da UNP, mas no } \\
\text { caso da UERN percebeu-se que as } \\
\text { demonstrações contábeis praticamente } \\
\text { não são usadas para essa finalidade. }\end{array}$ \\
\hline
\end{tabular}




\begin{tabular}{|c|c|c|}
\hline $\begin{array}{l}\text { Lizote et al. } \\
(2016)\end{array}$ & $\begin{array}{l}\text { Descrever o perfil } \\
\text { financeiro pessoal dos } \\
\text { alunos de graduação } \\
\text { em Ciências Contábeis } \\
\text { de uma Instituição de } \\
\text { Ensino Superior de Santa } \\
\text { Catarina. }\end{array}$ & $\begin{array}{l}\text { Os resultados demonstraram não haver } \\
\text { distinção, dentro da amostra pesquisada, } \\
\text { entre as características pessoais e } \\
\text { familiares com a percepção individual } \\
\text { sobre finanças pessoais. Além disso, } \\
\text { o fator relacionado ao constructo de } \\
\text { gestão de crédito, declarada como } \\
\text { "possuir financiamentos", não está } \\
\text { relacionado significativamente à } \\
\text { percepção dos entrevistados. }\end{array}$ \\
\hline $\begin{array}{l}\text { Cunha et al. } \\
(2017)\end{array}$ & $\begin{array}{l}\text { Analisar a contribuição } \\
\text { das disciplinas } \\
\text { ministradas no curso } \\
\text { de ciências contábeis, } \\
\text { que envolvem educação } \\
\text { financeira, para a gestão e } \\
\text { planejamento financeiro } \\
\text { pessoal dos acadêmicos. }\end{array}$ & $\begin{array}{l}\text { Os resultados evidenciam que na } \\
\text { percepção dos discentes pesquisados, } \\
\text { de modo geral, o conteúdo desenvolvido } \\
\text { durante o curso de graduação em } \\
\text { Ciências Contábeis contribui para o } \\
\text { conhecimento, gestão e planejamento } \\
\text { financeiro pessoal dos alunos. }\end{array}$ \\
\hline $\begin{array}{l}\text { Flores, Flores e } \\
\text { Martins (2020) }\end{array}$ & $\begin{array}{l}\text { Analisar a percepção } \\
\text { de alunos de Ciências } \\
\text { Contábeis de uma } \\
\text { universidade comunitária } \\
\text { de Santa Catarina em } \\
\text { relação às suas finanças } \\
\text { pessoais. }\end{array}$ & $\begin{array}{l}\text { Como resultado, identificou-se que } \\
\text { grande parte dos alunos possuem } \\
\text { conhecimento regular em relação ao } \\
\text { tema pesquisado. Mas também, que dão } \\
\text { grande importância para informações } \\
\text { voltadas à educação financeira pessoal } \\
\text { e concordam em sua grande maioria } \\
\text { que o ensino da educação financeira é } \\
\text { essencial para a formação do cidadão } \\
\text { brasileiro. }\end{array}$ \\
\hline
\end{tabular}

Fonte: Elaborado pelos Autores (2020).

Destaca-se que grande parte das pesquisas desenvolvidas busca identificar a percepção dos estudantes sobre terem ou não noções sobre educação financeira, se ganham ou possuem conhecimentos nos cursos de graduação que cursam, porém, o número de pesquisas que buscam visualizar como as ferramentas da contabilidade pode auxiliar os estudantes são mais escassas.

\section{METODOLOGIA}

A metodologia é a aplicação de procedimentos e técnicas que devem ser observados para construção do conhecimento, com o propósito de comprovar sua validade e utilizada nos diversos âmbitos da sociedade (PRODANOV; FREITAS, 2013). Ou seja, quando uma metodologia é aplicada cria-se a possibilidade de analisar e avaliar técnicas de pesquisa para se obter dados e, posteriormente, 
informações e resultados, tudo isso com objetivo final de resolver problemas da sociedade com questões que não foram investigadas.

A investigação pode ser relacionada como algo que é a busca de um projeto inacabado seja ela prática ou teórica, tendo como objetivo principal encontrar uma resolução ou resposta de determinado problema seja ele de uma pessoa física ou empresa (LAKATOS; MARCONI, 2001).

$\mathrm{O}$ trabalho foi realizado na Instituição de Ensino Superior de Marechal Cândido Rondon - Isepe Rondon, a qual possui os cursos de Administração, Agroindústria, Ciências Contábeis, Direito, Engenharia de Produção, Pedagogia e Psicologia.

Quanto à classificação da pesquisa frente a seus objetivos, ela se caracteriza como descritiva, que de acordo com Nunes, Nascimento e Luz (2016) possui o intuito de identificação, registro e análise das características, fatores ou variáveis que se associam com o fenômeno ou processo, possibilitando assim visões diferentes sobre uma realidade já conhecida.

Quanto aos procedimentos, o estudo caracteriza-se como uma pesquisa bibliográfica e de levantamento. Para Gil (2008) a elaboração da pesquisa bibliográfica é baseada em um material que já foi publicado e que, normalmente, inclui livros, revistas, jornais teses, material impresso e canais de eventos científicos.

No que diz respeito ao levantamento de dados, buscou-se interrogar um grupo de pessoas o qual se pretendeu analisar. De tal forma, e com base no estudo de caso foi possível analisar o problema e os principais fatores que o influenciam.

$\mathrm{Na}$ abordagem do problema, caracteriza-se como uma pesquisa de modo qualitativo e quantitativo, pois, conforme Michel (2009), na pesquisa qualitativa a verdade não é comprovada com números ou estatísticas, mas a partir de análise feita de maneira detalhada. Nessa os pesquisadores estão sempre preocupados com o processo, ou seja, para eles a preocupação maior está em conhecer os estipulados fenômenos. Já a quantitativa preocupa-se mais com os resultados e produtos (ZANELLA, 2009).

A forma de amostragem utilizada no trabalho foi não probabilística. A pesquisa aplicada para esse estudo se baseia em 18 questões que foram aplicadas de forma online aos discentes dos cursos da instituição de ensino superior Isepe Rondon, o propósito da investigação é fazer com o que os próprios discentes avaliem como a educação financeira e gestão das finanças pessoais podem auxiliar em sua vida financeira. O questionário foi dividido em três dimensões, sendo a análise do perfil dos respondentes, o perfil da formação e também o perfil econômico dos discentes.

De acordo com Teixeira (2003), a análise de dados é o processo de formação de sentido além da apresentação dos dados, e esta formação se dá 
consolidando, limitando e interpretando o que as pessoas disseram e o que o pesquisador viu e leu, isto é, o processo de formação do significado.

\section{RESULTADOS E DISCUSSÃO}

Neste capítulo, apresentam-se os resultados obtidos por meio da análise dos dados coletados no questionário aplicado. Primeiramente, serão apresentados os dados que são referentes ao perfil dos discentes; posteriormente, os dados que se referem à educação financeira e a forma com que os respondentes se comportam em relação às finanças pessoais na atualidade e também no futuro.

\subsection{Perfil dos respondentes}

Para análise do questionário, dividiu-se em três tópicos sendo esses a análise do perfil dos respondentes, o perfil da formação e também o perfil econômico dos acadêmicos. A primeira parte das perguntas teve a função de cumprir com o objetivo específico "a" do estudo, o qual teve a intenção de identificar o perfil dos respondentes no que diz respeito ao gênero, faixa etária, estado civil.

Dos 139 respondentes, $59,7 \%$ são do sexo feminino, enquanto $40,3 \%$ são do sexo masculino. No que tange à faixa etária, a maior parte dos respondentes estão entre as idades de 18 a 21 anos $(43,9 \%)$, com mais de 25 anos perfez $33,8 \%$, entre 22 a 25 anos são $19,4 \%$ e $2,9 \%$ com menos de 18 anos.

A Tabela 1 demonstra a distribuição dos 139 respondentes quanto ao seu estado civil. Nota-se que a maioria é solteiro $(72,7 \%)$ e $25,2 \%$ responderam serem casados.

Tabela 1: Estado civil dos respondentes

\begin{tabular}{ccc}
\hline Estado Civil & Quantidade & Porcentagem \\
\hline Solteiro & 101 & $72,7 \%$ \\
Casado & 35 & $25,2 \%$ \\
Divorciado & 2 & $1,4 \%$ \\
Viúvo & 1 & $0,7 \%$ \\
Total & 139 & $100,0 \%$ \\
\hline
\end{tabular}

Fonte: Elaborada pelos autores (2020).

Destaca-se ainda que, dos que estão solteiros ou casados, dentre os solteiros a faixa etária de 18 a 21 anos apresenta um percentual de $41,72 \%$. Já na faixa etária de mais de 25 anos há um percentual de $20,86 \%$ de casados.

4.2 Perfil da formação dos respondentes 
A segunda parte do trabalho teve o objetivo de averiguar o perfil da formação dos discentes, sendo composta por duas perguntas, para verificar qual curso e período está cursando. A Faculdade Isepe Rondon atualmente conta com os cursos de: Administração, Agroindústria, Ciências Contábeis, Direito, Engenharia de Produção, Formação de Docentes, Pedagogia e Psicologia. Com períodos letivos de quatro anos (oito semestres) a cinco anos (10 semestres). Em especial o curso de Agroindústria, que é tecnólogo, tem duração de quatro semestres.

Dos 139 respondentes, 44 são do curso de Direito (31,7\%), 27 são do curso de Administração (19,4\%), 20 cursam Ciências Contábeis (14,4\%), 20 pessoas pertencem ao curso de Engenharia de Produção (14,4\%), 15 alunos $(10,8 \%)$ são do curso de Psicologia, oito discentes cursam Pedagogia $(5,8 \%)$ e cinco discentes o curso de agroindústria (3,6\%), totalizando 139 acadêmicos.

Referente ao perfil de formação questionou-se quanto ao período que está cursando, sendo esses divididos em semestres, sendo que alguns cursos possuem oito semestres e outros 10 semestres, 45 discentes destacaram que estão no $7^{\circ}$ ou $8^{\circ}$ semestre, equivalendo a um percentual de $32,4 \%$, outros 39 , ou seja, $28,1 \%$ estão no $1^{\circ}$ ou $2^{\circ}$ semestre, 24 pessoas, $17,3 \%$, mencionam que estão no $3^{\circ}$ ou $4^{\circ}$ semestre, 18 acadêmicos, correspondendo a $12,9 \%$, informaram que estão no $5^{\circ}$ ou $6^{\circ}$ semestre e 13 discentes, $9,4 \%$, estão no $9^{\circ}$ ou $10^{\circ}$ semestre.

\subsection{Perfil econômico dos respondentes}

A terceira parte da pesquisa é composta por treze perguntas a qual teve o objetivo de averiguar o perfil econômico dos respondentes. A primeira pergunta teve o objetivo de constatar com quem os respondentes moram, pois, morar com familiar ou sozinho tem uma grande influência no perfil econômico. A maioria dos acadêmicos, $56,1 \%$, correspondendo a 78 respondentes, ainda reside com os pais ou família, 32,4\% moram com companheiro (a) totalizando 45 respostas, 10,1\%, ou seja, 14 discentes, moram sozinhos, e duas pessoas dividem apartamento ou casa com os amigos perfazendo 1,4\%, como representado na Tabela 2 .

Tabela 2: Com quem os respondentes residem

\begin{tabular}{lcc}
\hline & Frequência & Porcentagem \\
\hline Com meus pais/ou família & 78 & $56,1 \%$ \\
Com meu/meu companheiro & 45 & $32,4 \%$ \\
Sozinho & 14 & $10,1 \%$ \\
Divido apartamento/casa com amigos & 2 & $1,4 \%$ \\
\multicolumn{1}{c}{ Total } & 139 & $100,0 \%$ \\
\hline
\end{tabular}

Fonte: Elaborada pelos autores (2020). 
$\mathrm{Na}$ sequência, questionou-se sobre qual a fonte de renda dos respondentes, essa pergunta engloba emprego formal, emprego informal, profissional autônomo, estágio, auxílio/bolsa e mesada, sendo que dos 139 respondentes 95 acadêmicos, ou $68,3 \%$ destacam que sua fonte de renda vem de emprego formal, 20 discentes, correspondendo a 14,4\% informaram que sua renda é proveniente de estágio, 10 pessoas, ou seja, 7,2\% são profissionais autônomos, já com emprego informal obteve $4,3 \%$ respostas totalizando seis pessoas e com o mesmo percentual, $4,3 \%$ e seis pessoas destacaram que recebem mesada, finalizando com dois acadêmicos com um percentual de $1,4 \%$, que a renda é proveniente de auxílio/bolsa.

A terceira questão teve a finalidade de verificar a situação econômica, ou seja, de como os discentes fazem suas compras. O Gráfico 1 apresenta as informações relacionadas à forma de realização de compras pelos acadêmicos.

Figura 1: Forma de realização das compras

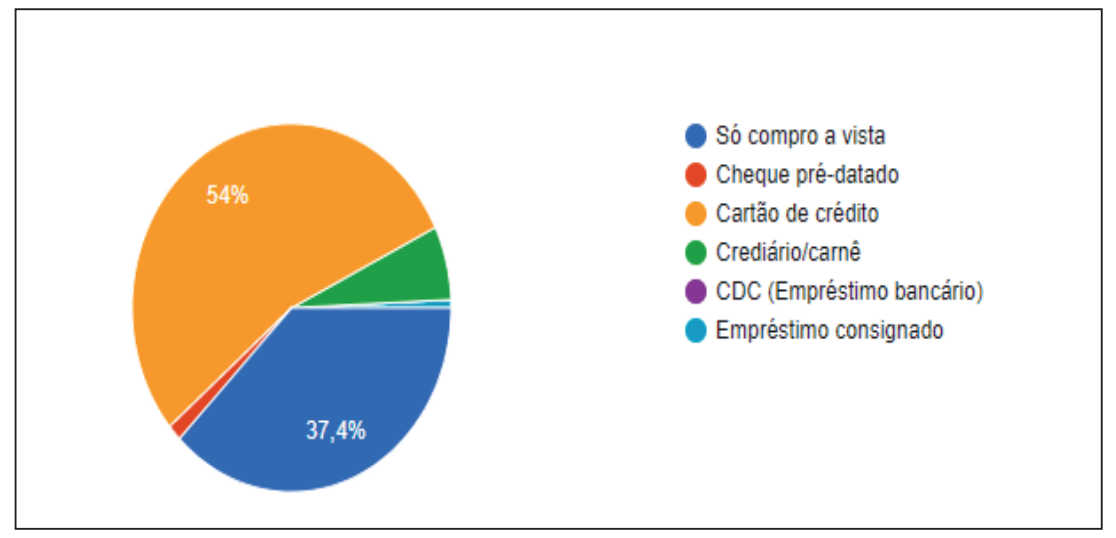

Fonte: Elaborado pelos autores (2020).

Nessa pergunta foram colocadas como opção as respostas: cartão de crédito, só compro à vista, cheque pré-datado, crediário/carnê, CDC (empréstimo bancário) e também a opção de crédito consignado. Destas alternativas, a maioria informou que realiza suas compras por meio de cartão de crédito com um percentual de $54 \%$ e um número de 75 respondentes, já a outra grande parcela informou que só faz compras à vista com um percentual de $37,4 \%$ e um total de 52 acadêmicos, os demais nove discentes informaram que utilizam o meio de crediário ou carnê com um percentual de $6,5 \%$ e dois respondentes com um percentual de $1,4 \%$, destacaram que usam cheques pré-datados como meio de pagamento, apenas uma pessoa respondeu que usa como meio de pagamento 
empréstimo consignado com $0,7 \%$ e nenhuma pessoa informou que faz o uso de CDC (empréstimo bancário) para realizar suas compras.

A próxima questão teve o objetivo de verificar se os respondentes consideram-se endividados, com a opção de sim e não, dos 139 respondentes 117 responderam que "Não" com um percentual de $84,2 \%$ e 22 pessoas mencionaram que "Sim" com um percentual de 15,8\%.

$\mathrm{Na}$ sequência, quetionaram-se os discentes se esses fazem o monitoramento ou controle dos seus gastos, também a opção de sem e não, dos 139 respondentes, a maioria com um percentual de 87,8\% disse que "Sim", que faz o controle de seus gastos, totalizando assim 122 e 17 acadêmicos que afirmaram "Não" fazer controle dos seus gastos perfazendo 12,2\%.

Para examinar sobre a administração dos gastos, questionou-se como os respondentes administram seus gastos durante o mês, as opções foram as seguintes: Gasto uma parte do meu dinheiro, mas reservo um valor para guardar ou investir; Geralmente gasto todo meu dinheiro e às vezes guardo um parte ou invisto; Gasto todo meu dinheiro, para suprir minhas necessidades, mas não fico com nenhuma dívida pendente; Gasto todo meu dinheiro e às vezes fico com alguma dívida pendente; Gasto todo meu dinheiro e sempre fico com alguma dívida pendente, conforme apresentado na figura 2.

Figura 2: Administração dos Gastos

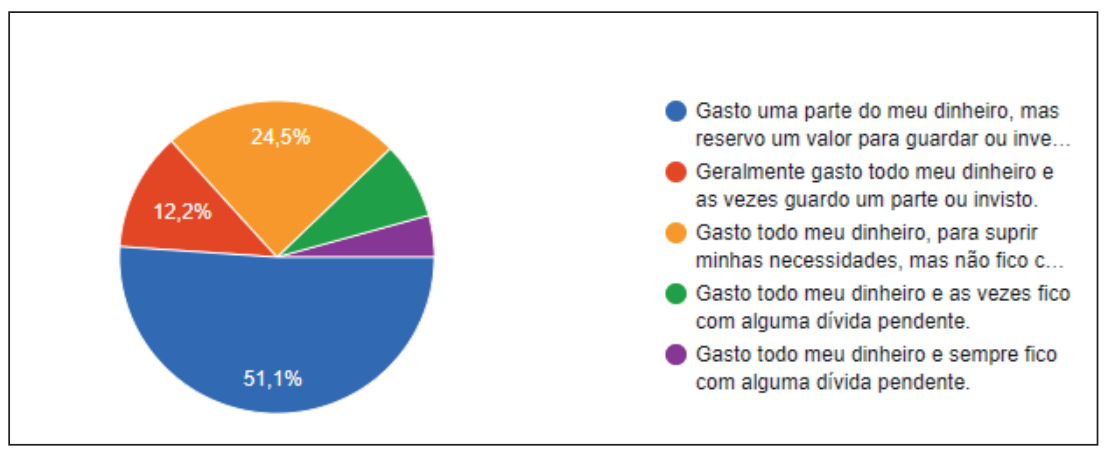

Fonte: Elaborado pelos autores (2020).

A maioria dos acadêmicos, ou seja, $51,1 \%$, destacou que gasta uma parte do dinheiro, mas reserva um valor para guardar ou investir perfazendo 71 respondentes, por outro lado, 24,5\%, 34 discentes gasta todo o dinheiro, para suprir suas necessidades, mas não fica com nenhuma dívida pendente, já $12,2 \%$, totalizando 17 dos respondentes geralmente gasta todo o seu dinheiro e às vezes guarda uma parte ou investe, outras 11 pessoas informaram que gastam todo o 
dinheiro e às vezes ficam com alguma dívida pendente com um percentual de $7,9 \%$ e seis acadêmicos, destacam que gastam todo o dinheiro e sempre ficam com alguma dívida pendente perfazendo de $4,3 \%$.

Dos respondentes 33,81\% são acadêmicos dos cursos de administração e Ciências Contábeis, cursos que estão diretamente relacionados com finanças, seja pessoal ou jurídica. Sendo que desses $57,44 \%$ gastam parte de seu dinheiro e reservam parte para investir, $14,90 \%$ geralmente gastam todo o dinheiro e às vezes guardam e $27,66 \%$ gastam todo o seu dinheiro, mas não ficam com dívidas. Comparando com os demais cursos, o percentual demonstra que os acadêmicos de Administração e Ciências Contábeis, apresentam maior controle sobre os gastos.

Para averiguar se os discentes fazem ou possuem algum tipo de controle das suas finanças pessoais, questionou-se sobre a forma de controle de gastos. As opções de respostas foram: Controlo meus gastos por meio de aplicativos; controlo por meio de planilhas e/ou anotações em cadernos; controlo esporadicamente com planilhas e/ou anotações; controlo os gastos na minha mente, e não tenho nenhum tipo de controle.

Dos 139 acadêmicos, 32,4\% destacam que controlam seus gastos por meio de planilhas e/ou anotações totalizando 45 respondentes, 23,7\% mencionaram que controlam seus gastos em sua mente, perfazendo 33 respostas, $22,3 \%$, ou seja, 31 acadêmicos destacaram que controlam seus gastos por meio de aplicativos, 14,4\% afirmaram que controlam apenas esporadicamente através de planilhas e/ou anotações com 20 respostas e 10 respondentes afirmaram que não tem nenhum tipo de controle com um percentual de $7,2 \%$, percebe-se que mais da metade dos acadêmicos, ou seja, $54,7 \%$ utilizam as ferramentas da contabilidade como forma de controle da gestão das finanças pessoais.

Na sequência perguntou-se aos discentes onde eles gastam a maior parte do seu dinheiro, as opções para essa pergunta foram as seguintes: alimentação, produtos de beleza, vestuário, transporte, aluguel ou contas da casa, lazer ou diversão, outros e não sei dizer. Conforme se observou a maioria com $28,1 \%$ respondeu "outros" com um total de 39 respondentes, ou seja, a maior parte dos respondentes gasta seu dinheiro com outras coisas a não ser o básico de uma rotina comum.

Despesas com aluguel ou contas da casa perfez 35 respondentes com $25,2 \%$, já o gasto com alimentação obtive $23 \%$ das respostas, totalizando 32 acadêmicos, $11,5 \%$ destacaram que gasta com lazer ou diversão, perfazendo 16 pessoas, a opção de não sabem dizer com o que mais gastam obteve sete respostas com um percentual de $5 \%$, já os gastos com vestuário teve seis respondentes, ou seja, $4,3 \%$, os gastos com produtos de beleza foi mencionado por três discentes perfazendo $2,2 \%$ e apenas uma pessoa afirmou que seu maior gasto é com 
transporte. Dessa forma, podemos perceber que há uma variação bastante grande do perfil de gastos dos respondentes e que 5\% dos respondentes não souberam dizer com o que mais gastam.

Para conferir quais eram suas maiores dificuldades para investir seu dinheiro, foram dadas como opções a seguintes afirmativas: Não sobra dinheiro no final do mês, não tenho renda fixa, falta de conhecimento sobre investimentos, não acho necessário investir, prefiro só guardar dinheiro para alguma necessidade. A Tabela 3 demonstra as maiores dificuldades elencadas.

Tabela 3: Quais as maiores dificuldades de investir seu dinheiro

\begin{tabular}{lcc}
\hline & Frequência & Porcentagem \\
\hline Não sobra dinheiro no final do mês & 53 & $38,10 \%$ \\
Não tenho renda fixa & 11 & $7,9 \%$ \\
Falta de conhecimento sobre investimentos & 57 & $41 \%$ \\
Não acho necessário investir, somente para & 18 & $12,9 \%$ \\
necessidade & 139 & \\
Total &
\end{tabular}

Fonte: Elaborada pelos autores (2020).

Dos 139 respondentes a maioria $41 \%$, ou seja, 57 acadêmicos destacaram que pela falta de conhecimento sobre investimentos tem dificuldade para investir. Outros 38,1\% afirmaram que não sobra dinheiro no final do mês para investir, com um total de 53 pessoas, $12,9 \%$ mencionaram que não acham necessário investir e que preferem apenas guardar dinheiro para alguma necessidade, com um total de 18 respostas e 11 discentes afirmaram que não investem por não possuírem renda fixa.

Perguntou-se ainda sobre a educação financeira e de qual forma eles aprenderam sobre o assunto, sendo que as opções a serem respondidas eram: Com meus pais e/ou familiares, com amigos, na internet e/ou livros, já ouvi falar, mas não procurei me informar muito sobre o assunto e nunca tive nenhum contato. Diante das opções $38,1 \%$, correspondendo a 53 acadêmicos, que já viram na internet e/ou livros, $25,2 \%$ discentes que já ouviram falar, porém não procuraram se informar sobre o assunto totalizando 35 pessoas, $17,3 \%$ mencionaram que já tiveram contato por meio de seus pais e/ou familiares, perfazendo 24 respondentes e cinco destacam que tiveram contato com a educação financeira por meio de amigos totalizando $3,6 \%$.

Objetivando identificar a visão dos acadêmicos da instituição referente à educação financeira, foi indagado se consideram importante os cursos abordarem a educação financeira pessoal nas universidades, e as opções foram as seguintes: 
Todos os cursos deveriam ensinar esse assunto, pois é algo voltado para ajudar na qualidade de vida das pessoas; Apenas os cursos da área financeira e afins que deveriam abordar o assunto, pois é algo restrito a determinados cursos; Nenhum curso deveria ensinar sobre isso, pois não é algo relevante; não sei dizer.

Para a maioria dos respondentes todos os cursos deveriam ensinar esse assunto, pois é algo voltado para ajudar na qualidade de vida das pessoas com $87,1 \%$, totalizando 121 respondentes, 12 destacam que apenas os cursos da área financeira e afins deveriam abordar o assunto, pois é algo restrito a determinados cursos com percentual de $8,6 \%$, outros cinco respondentes, ou seja, 3,6\%, destacaram que não sabem dizer e apenas uma pessoa disse que nenhum curso deveria ensinar sobre isso, pois não é algo relevante.

$\mathrm{Na}$ sequência, questionou-se os discentes se eles fazem algum tipo de investimento (poupança, renda fixa, renda variável, etc) respondendo com "Sim" ou "Não". Os acadêmicos que fazem algum tipo de investimento perfazem 67,6 \%, ou seja, 94 respondentes, já 45 respondentes, 32,4\% mencionam que "Não" fazem investimentos.

A última questão teve o objetivo de saber o que os discentes pensam sobre o futuro financeiro, foram dadas as seguintes alternativas: Não tem preocupação; Tem preocupação, mas não faz nada em relação a ele; já tem planejamento, mas ainda não colocou em prática; tem planejamento, já colocou em prática e o segue rigorosamente. Os resultados obtidos foram que $56,1 \%$ já têm planejamento, mas ainda não colocou em prática com 78 acadêmicos, já 21,6 \% afirmaram que têm preocupação, mas não faz nada em relação totalizando 30 respostas, para 29 discentes o planejamento já foi colocado em prática e o segue rigorosamente, com um percentual de $20,9 \%$ e apenas duas respostas afirmaram que não tem preocupação com o futuro financeiro.

\section{CONCLUSÃO}

A presente pesquisa teve como objetivo analisar se os discentes da Faculdade de Ensino Superior - Isepe Rondon, utilizam a contabilidade como ferramenta na gestão das finanças pessoais e qual a percepção desses frente à relevância da educação financeira nos cursos superiores. Para tanto, aplicou-se um questionário aos acadêmicos da Faculdade de Ensino Superior de Marechal Cândido Rondo - Isepe Rondon. No qual é possível perceber que 54,7\% dos acadêmicos fazem utilização de ferramentas como planilhas ou aplicativos para controle das finanças pessoais, evidenciando o uso da contabilidade como ferramenta na gestão financeira pessoal, mostrando que a questão problema foi respondida e o objetivo alcançado.

Buscou-se primeiramente identificar o perfil dos acadêmicos, sendo que 
$59 \%$ são do sexo feminino, quanto à faixa etária $66,2 \%$ possuem com menos de 25 anos e $72,7 \%$ são solteiros. Outro objetivo está relacionado à maneira como os acadêmicos aprenderam sobre educação financeira, destacando que $15,8 \%$ dos respondentes nunca tiveram contato com o tema abordado, o que evidencia a importância de se trabalhar o assunto durante a graduação. Ademais, 87,10\% dos acadêmicos destacam que os cursos superiores devem abordar sobre o tema durante as aulas, atingindo assim o objetivo sobre a visão dos acadêmicos frente à educação financeira pela instituição de ensino.

A pesquisa teve como propósito também verificar se os discentes guardam parte de sua renda para investimentos, sendo que $51,1 \%$ guardam parte da renda para investimentos. Destaca-se também que $15,8 \%$ consideramse endividados, $12,2 \%$ mencionam que não controlam os gastos e $4,3 \%$ gastam todo o ganho e ainda ficam devendo. Percebe-se que a maioria considera que as finanças pessoais estão boas, pois ainda conseguem guardar parte da renda recebida para investimentos.

Outro objetivo está relacionado ao nível de conhecimento dos acadêmicos em relação às finanças pessoais, sendo que $32,4 \%$ controlam as finanças por meio de planilhas e 22,3\% com aplicativos, e apenas 7,2\% afirmam não controlar os gastos.

Conclui-se neste estudo que os acadêmicos da instituição possuem um bom conhecimento frente ao tema, utilizam as ferramentas contábeis para os controles financeiros e consideram importante o ensino de finanças pessoais durante o curso superior,

Portanto a pesquisa contribuiu para destacar a importância de um controle das finanças pessoais, visto que, a maioria dos acadêmicos a realizam e, em contrapartida, apenas $12,2 \%$ não controlam os seus gastos e 4,3\% gastam tudo o que ganham e ficam endividados.

Por fim, sugere-se que mais estudos sejam desenvolvidos a respeito desse assunto, com o intuito de dar continuidade a essa temática que é tão importante para a sociedade em geral e também às instituições de ensino ou empresas de diferentes áreas, em outros municípios, sejam do setor privado ou público.

\section{REFERÊNCIAS}

ADRIANO, S. A contabilidade na gestão das finanças pessoais: um estudo comparativo entre discentes do curso de Ciências Contábeis. São Paulo: Método, 2012.

ALVES, R. A.; SILVA, S. S.; BRESSAN, A. A. educação financeira: uma 
lacuna na formação discente na área de contabilidade? In: CONGRESSO NACIONAL DE ADMINISTRAÇÃO E CIÊNCIAS CONTÁBEIS, 2., 2011, Rio de Janeiro. Anais [...]. Rio de Janeiro, 2011.

ANDRADE FILHO, E. O. Planejamento tributário. 2. ed. São Paulo: Saraiva, 2015.

CORREIA, T. S.; LUCENA, W. G. L.; GADELHA, K. A. D. L. Decisões financeiras $\mathrm{x}$ formação acadêmica: uma contribuição com base na educação financeira. CONGRESSO UFSC DE CONTROLADORIA E FINANÇA, 5., Florianópolis. Anais [...]. Florianópolis, 2014.

CUNHA, C. G. et al. Impacto das pesquisas de preço nas finanças pessoais. In: SEMINÁRIO CIENTÍFICO DA FACIG, 2, 2016, Manhuaçu. Anais [...]. Manhuaçu: FACIG, 2016.

FABRETTI, L. C. Prática tributária da micro, pequena e média empresa. 7. ed. São Paulo: Atlas, 2009.

FERRARI, E. L. A contabilidade na gestão das finanças pessoais: um estudo comparativo entre discentes do curso de ciências contábeis. Atualizada pelas Leis n 11.638/2007 E 11.941/2009 e pelas normas do Comitê de Pronunciamentos Contábeis (CPC). 11. ed. Rio de Janeiro: Impetus, 2011.

FLORES, E. G.; FLORES, A. G.; MARTINS, Z. B. Finanças pessoais: um estudo com alunos de graduação em Ciências Contábeis de uma Universidade Comunitária de Santa Catarina. Revista Conhecimento Contábil, v. 10, n. 2, p. 39-56, 2020.

FRANCO, H. Contabilidade geral. 23. ed. São Paulo: Atlas 1997.

FREITAG, V. C. et al. A contabilidade para controle das finanças pessoais: a visão do acadêmico. In: SEMINÁRIOS EM ADMINISTRAÇÃO (SEMEAD), 12, 2009, São Paulo. Anais [...]. São Paulo, 2009.

GALLAGHER, L. Planeje seu futuro financeiro: o guia sobre investimentos para multiplicar seu patrimônio. Rio de Janeiro: Elsevier, 2008.

GIL, A. C. Métodos e técnicas de pesquisa social. 6. ed. São Paulo: Atlas, 2008. 
GILLIGAN, H. L. An examination of the financial literacy of California College Students. Doctoral Dissertation, College of Education California State University, Long Beach, 2012.

GITMAN, L. J. Princípios de administração financeira: essencial. 2. ed. Porto Alegre: Bookman, 2001.

HORNGREN, C. T. Introdução à contabilidade gerencial. Rio de Janeiro: LTC, 1985.

LAKATOS, E. M.; MARCONI, M. A. Fundamentos metodologia científica. 4. ed. São Paulo: Atlas, 2001.

LIZOTE, S. A.; SIMAS, J.; VERDINELLI, M. A.; LANAS, J. Finanças pessoais: um estudo envolvendo os alunos de ciências contábeis de uma instituição de ensino superior. Revista da Unifebe, v. 1, n. 19, p. 71-85, 2016.

LIZOTE, S. A.; VERDINELLI, M. A. Educação Financeira: um Estudo das Associações entre o Conhecimento sobre Finanças Pessoais e as Características dos Estudantes Universitários do Curso de Ciências Contábeis. In: CONGRESSO USP DE CONTROLADORIA E CONTABILIDADE, 14., 2014, São Paulo. Anais [...]. São Paulo, 2014.

LOPES, A. V. et al. Alfabetização financeira dos alunos dos cursos de administração de empresas, economia e ciências contábeis da FECAP. Revista Liceu Online, v. 4, n. 5, p. 53-71, 2014.

MACEDO JUNIOR J. A árvore do dinheiro: guia para cultivar sua independência financeira. Coleção expo Money. Rio de Janeiro: Elsevier, 2007.

MARION, J. C. Contabilidade aplicada às finanças pessoais: um estudo de caso com os acadêmicos do Centro Universitário municipal de São José. 7. ed. São Paulo: Atlas, 2004.

MARION, J. C. Contabilidade empresarial. 7. ed. São Paulo: Atlas, 1998.

MEDEIROS, F. S. B.; LOPES, T. de A. M. Finanças pessoais: um estudo com alunos do Curso de Ciências Contábeis de uma IES privada de Santa Maria RS. Revista Eletrônica de Estratégia \& Negócios, v. 7, n. 2, p. 221-251, 2014.

MICHEL, M. H. Metodologia e pesquisa científica aplicada em ciências 
sociais. 2. ed. São Paulo: Atlas, 2009.

MIRANDA, M. O. R. A educação financeira e sua influência no planejamento de finanças pessoais dos alunos da Fatecs do Uniceub. 2013. Trabalho de Conclusão de Curso (Graduação em Administração) - Centro Universitário de Brasília, Brasília, 2013. Disponível em: http://repositorio. uniceub.br/bitstream/235/4971/1/20953505.pdf. Acesso em: 17 maio 2020.

NEGRI, A. L. L. Educação financeira para o ensino médio da rede pública: uma proposta inovadora. 2010. Dissertação (Mestrado em Educação) - Centro Universitário Salesiano de São Paulo, São Paulo, 2010. Disponível em: http:// unisal.br/wpcontent/uploads/2013/04/Disserta\%C3\%A7\%C3\%A3o_AnaLucia-Lemes-Negri.pdf. Acesso em: 17 maio 2020.

NUNES, G. C.; NASCIMENTO, M. C. D.; ALENCAR, M. A. C. de. Pesquisa científica: conceitos básicos. Revista de Psicologia, n. 10, v. 29, p. 144-151, 2016.

OLIVEIRA, A. B. S. A contabilidade gerencial e sua importância na atualidade. São Paulo: Saraiva, 2009.

PADOVEZE, C. L. Contabilidade gerencial. Curitiba: IESDE Brasil, 2012.

PARADA, A. Introdução à contabilidade. 15 abr. 2011. Disponível em: www. cosif.com.br/mostra.asp?arquivo=contabilidade00. Acesso em: 27 jun. 2020.

PIZZOLATO, N. D. Introdução à contabilidade gerencial. 5. ed. São Paulo: LTC, 2012.

POHLMANN, M. C. Contabilidade tributária. Curitiba: IESDE Brasil, 2010.

PRODANOV, C. C.; FREITAS, E. C. de. Metodologia do trabalho científico: métodos e técnicas da pesquisa e do trabalho acadêmico. 2. ed. Rio Grande do Sul: Feevale, 2013.

QUEIROZ, E. H. de; VALDEVINO, R. Q.; OLIVEIRA, A. M. de. A Contabilidade na gestão das finanças pessoais: um estudo comparativo entre discentes do curso de Ciências Contábeis. Revista Conhecimento Contábil, v. 1, n. 1, 2015.

RIBEIRO. O. M. Contabilidade de custos fácil. 8. ed. São Paulo: Saraiva, 
2013.

SÁ, A. L. de. A contabilidade gerencial e sua importância na atualidade. São Paulo: Atlas, 1971.

SILVA, W. J. da; CARRARO, W. B. W. H.; DA SILVA, M. D. L. F. A Contabilidade como instrumento de controle e planejamento financeiro pessoal. CONGRESSO DE CONTABILIDADE DA UFRGS, 2., 2017, Porto Alegre. Anais [...]. Porto Alegre: URGS, 2017.

SOUSA, F.; DANA, S. Como passar de devedor para investidor. São Paulo: Cengage Learning, 2012.

STEIGER, G. A.; BRAIDO, G. M. Finanças pessoais na adolescência: conhecimento financeiro dos estudantes de ensino médio das escolas públicas da comarca de arroio do meio/RG. In: SIMPÓSIO DE ADMINISTRAÇÃO DA PRODUÇÃO, LOGÍSTICA E OPERAÇÕES INTERNACIONAIS, 2016, São Paulo. Anais [...] São Paulo: SIMPOI, 2016.

TEIXEIRA, E. B. A análise de dados na pesquisa científica: a importância e desafios em estudos organizacionais. Desenvolvimento em questão, v. 1, n. 2, p. 177-201, dez. 2003. Disponível em: https:www.revistas.unijui.edu.br/index. php/desenvolvimentoemquestao/article/view/84. Acesso em: 10 jun. 2020.

VIEIRA, S. F. A.; BATAGLIA, R. T. M.; SEREIA, V. J. Educação financeira e decisões de consumo, investimento e poupança: uma análise dos alunos de uma universidade pública do norte do Paraná. Revista de Administração da Unimep, v. 9, n. 3, p. 61-86, 2011.

ZANELLA, L. C. H. Metodologia de estudo e de pesquisa em administração. Brasília: Capes: UAB, 2009.

Recebido em: 10/02/2021

Aceito em: 29/03/2021 